\title{
Effect of technological parameters on vibration acceleration in milling and vibration prediction with artificial neural networks
}

\author{
Ireneusz Zagórski ${ }^{1}$, and Monika Kulisz ${ }^{2, *}$ \\ ${ }^{1}$ Lublin University of Technology, Faculty of Mechanical Engineering, Department of Production Engineering, Nadbystrzycka 36, 20- \\ 618 Lublin, Poland \\ ${ }^{2}$ Lublin University of Technology, Faculty of Management, Department of Organisation of Enterprises, Nadbystrzycka 38, 20-618 \\ Lublin, Poland
}

\begin{abstract}
This paper reports on the study of vibration acceleration in milling and vibration prediction by means of artificial neural networks. The milling process, carried out on AZ91D magnesium alloy with a PCD milling cutter, was monitored to observe the extent to which the change of selected technological parameters $\left(v_{c}, f_{z}, a_{p}\right)$ affects vibration acceleration $a_{x}, a_{y}$ and $a_{z}$. The experimental data have shown a significant impact of technological parameters on maximum and RMS vibration acceleration. The simulation works employed the artificial neural networks modelled with Statistica Neural Network software. Two types of neural networks were employed: MLP (Multi-Layered Perceptron) and RBF (Radial Basis Function).
\end{abstract}

\section{Introduction}

Vibration is a physical phenomenon that normally accompanies milling and which is a significant factor deciding whether the machined element will exhibit high quality of finish and maintain specified parameters. Vibrations in milling are considered as an additional indicator of machinability. The phenomenon is highly undesirable during machining, particularly when occurring in the form of self-excited vibration, i.e. chatter, which occurs between the tool and the workpiece (as a result of temporary surface disproportions). The consequences of vibrations include: poor quality of surface finish, dynamic tool wear (resulting from the increased friction and subsequent elevated temperature in the cutting area) [1] and even damage of machine tool components, or decrease in machining accuracy. Accelerated wear is predominantly observed on surfaces actively involved in machining, and in permanent or temporary joints [2]. Moreover, vibrations induced during milling hamper the efficiency of machining and are potentially disruptive to the entire production process (loss of control over the process) [16]. Besides, excessive vibration levels pose risk to the machine tool operators' health [3-5]. Vibration typically concerns the tool and workpiece, and the effects of vibrations may lead to extremely negative outcomes from the viewpoint of production, inasmuch as they make it impossible to predict the characteristics of the finished product (i.e. attaining the target dimensional and shape accuracy and surface quality). The counterproductive nature of vibrations is particularly tangible in finishing operations [6] and milling of thin- walled components [7-9]. In order to ensure the desired stability of the process, we typically employ stability lobe diagrams; an alternative solution is recurrence quantification analysis, which is an effective tool for the determination of stability lobes for workpieces of nonuniform (decreasing) wall thickness.

It appears therefore that the central issue in milling should be to specify technological conditions that will ensure the stability of the process through preventing vibration $[10,11]$. To that end, various specialist software is employed to determine stable machining parameters in given applications. Key parameters of milling with regards to process stability are: axial depth of cut $a_{p}$ and spindle speed $n$. In the era of modern sophisticated high-technology cutting tools, machine tools and materials, controlling and modelling the mill cutting process become increasingly important. In the search for efficiency and cost-effectiveness new methods are being constantly developed to address the problem of vibration of the cutting tool and workpiece $[2,5]$.

\section{State of the art}

Vibrations are undesired by-products of technological operations and processes, which are virtually impossible to eliminate. The major determinants of their intensity are predominantly the operating conditions of the machine tool, wear of particular elements, consistency of environmental conditions or sudden workload changes. Vibration is to a certain degree possible to limit and maintain at low level. However, in order to do so it imperative to determine the interrelationships between particular machine elements and their behaviour during work. Determination of vibration source sets the

*Corresponding author: m.kulisz@pollub.pl 
direction for the development of machine tools design and technology, as it enables implementation of solutions guaranteeing stable machining at increasing cutting speeds $[2,6]$.

There range of techniques devised to prevent selfexcited vibration is nevertheless quite wide, and includes: numerical simulations and process dynamics modelling, the use of actuators (automation devices), pulsation of spindle speed frequency or increasing feed per tooth rate. According to [12], vibration prevention methods may be classified into two major groups. Group one embraces techniques that provide machining stability through selection of stable machining parameters from the stability lobe diagram, whereas group two - methods concerning the system behaviour change and adjustment of stability lobes.

Another work [13] presents an overview of chatter damping methods; and furthermore describes the method selection based on various aspects of the machining process, e.g. material machinability and stiffness within the machine-tool-workpiece-fixture system. The work also describes how to develop a stable process with the application of stability lobe diagrams. The diagrams are developed using a stability model based on the components of the cutting force, dynamic and technological parameters of milling and tool geometry. SLD-based analyses [14] account for the effect of tool diameter on emergence of vibration in milling. The study concludes that the increase in the tool diameter increases stability lobes. Furthermore, the increase in the number of the cutter teeth results in the tendency of SLDs to move right (the increase of the range of $n$ ).

The SLD technique, however, is burdened with certain drawbacks. The data implemented for the development of SLDs are obtained from the analysis of the machine tool conducted during its down time. Consequently, there are certain factors that are not included in the analysis, such as rigidity of the spindle assembly and potential impact of elevated temperature of machine tool elements during milling, as well as factors related to the workpiece (e.g. damping properties arising from the machined component's mass, potential material flaws or the non-uniform diameter of the area of cut) $[13,15]$.

In summary, the methods for the prevention and damping of self-excited vibrations are based on: adjustment of technological parameters of machining, or readjustment of the machine tool design. The disadvantages of both approaches include their purely predictive rather than reactive character, which determines that any observations carried out in the process are not accounted for [16]. Bearing in mind the cost and time consumption of their implementation, it would appear that adjustment of process parameters is a more feasible solution. Among the modifiable parameters of milling, it would seem that is the spindle speed that might be the most essential component of the entire process [17]. A properly defined optimal value of $\mathrm{n}$ guarantees the absence of chatter and the resulting increase of efficiency, and may be furthermore modelled on a virtual machine with the implementation of the methodology for the selection of stable spindle speeds.
This solution requires such data as: the number of cutter teeth in the tool and chatter frequency [18]. The offline procedure is carried out according to the following plan: chatter detection, deactivation of feed, adjustment of spindle speed, recommencement of cutting. The procedure for the online method is based on continuous chatter control and immediate adjustment of spindle speed should chatter occur - the entire process does not involve the interference in feed [19].

At present, the use of HPC milling is slowly becoming a standard in machining. In High-Performance Cutting the material is subtracted at a significant rate at short time. Work [20] analyses the potential of diagnosing the HPC milling of $\mathrm{AlZn} 5.5 \mathrm{MgCu}$ (EN AW7075 ) aluminium alloy with the use of signals obtained from the cutting forces, acoustic emission and vibration. In HPC milling the key element from the viewpoint of diagnostics is the signal of the passive force component of the cutting force $F_{p}$. Owing to the high cost of specialised dynamometers and their complicated set-up, the determination of the passive force component may be substituted by e.g. RMS acoustic emission measurement or vibration measurement. The registered signals of acoustic emission exhibit a significant correlation with the passive force component values and are additionally highly resistant to background noise while exhibiting sufficient sensitivity. The main advantage of vibration amplitude measurement with accelerometer is that it provides data regarding the course of the process and shows a comparably good correlation with the force signal, however, it is rather susceptible to interference (the sensor attachment point is highly important).

Neural network modelling of machining dynamics is an exciting, powerful and yet not fully harnessed method [21]. When implemented, it may facilitate the choice of most suitable technological parameters, which foster optimisation of milling cutting (efficiency boost) [22, 23]. The major advantage of computer simulation is that it does not require any experimental testing, and consequently limits the use of cutter tools and machine tools. Developed models enable specification of technological parameters that ensure the lowest possible vibration. It is therefore particularly important to determine stable machining parameters, which will prevent vibrations, and particularly self-excited chatter. Neural network simulations enable initial determination of process parameters and vibration components prediction [4].

\section{Test and simulation methodology}

\subsection{The specification of test}

The presented study was carried out for magnesium AZ91D cast alloy workpiece material ( $\left.\mathrm{MgAl}{ }_{9} \mathrm{Zn} 1\right)$, which is a cast alloy commonly found in industrial applications, which is characterised by good mechanical properties and corrosion resistance. Mill cutting was performed on AVIA VMC $800 \mathrm{HS}$ vertical machining centre with Heidenhain iTNC $530 \mathrm{CNC}$ control. The milling process was carried out with a cutter tool Guhring PCD - Fraser MN-R 05492-16.001, $\lambda_{\mathrm{s}}=0^{\circ}$, clamped with a thermal-shrink tool holder SECO 
HSKA63 SFD 16x120, which protects the cutter tool from withdrawal from the assembly and minimises tool run-out. The entire assembly (tool holder + tool) was subsequently balanced with the use of CIMAT CMT$15 \mathrm{~V} 2 \mathrm{~N}$ balancer, in accordance with the International Standard ISO 1940: 2003. Balance quality grade was selected according to the specifications for machine tooldrive unbalance evaluation: $G \quad 2.5$ and 25,000 revolutions per minute. The norm allows for a slight permissible residual unbalance tolerance of $1 \mathrm{~g} \cdot \mathrm{mm}$, whereas for the analysed PCD milling cutter the residual unbalance was $1.03 \mathrm{~g} \cdot \mathrm{mm}$. The vibration measurement was carried out with SeTAC accelerometer (Triaxial Acceleration Computer) provided by SEQUOIA, composed of PCB 352B10 accelerometer based on MEMS technology (Micro-Electro-Mechanical Systems). The measuring instrument was fixed in the vice of the machine tool together with the magnesium alloy component. The technical specifications of the accelerometer are: measurement range $\pm 18 \mathrm{~g}$, dynamic range - from $85 \mathrm{~dB}$ at $10 \mathrm{~Hz}$, resolution $1 \mathrm{mg}$ at $10 \mathrm{~Hz}$. The ranges of modifiable technological parameters of machining in tests were: cutting speed $\mathrm{v}_{\mathrm{c}}=400 \div 1200$ $\mathrm{m} / \mathrm{min}$, feed per tooth $\mathrm{f}_{\mathrm{z}}=0.05 \div 0.3 \mathrm{~mm} /$ tooth, axial depth of cut $a_{p}=1 \div 6 \mathrm{~mm}$; while radial depth of cut $\mathrm{a}_{\mathrm{e}}=$ $14 \mathrm{~mm}$ was constant throughout all milling operations. The output data in the neural network model was vibration acceleration, vibration amplitude and RMS vibration. The results obtained from the experimental tests were subsequently visualised in the form of boxand-whisker plots and maximum values of vibration acceleration $\mathrm{a}_{\mathrm{x}}, \mathrm{a}_{\mathrm{y}}, \mathrm{a}_{\mathrm{z}}$, vibration amplitudes $\mathrm{Aa}_{\mathrm{x}}, \mathrm{Aa}_{\mathrm{y}}$, $\mathrm{Aa}_{\mathrm{z}}$, and RMS vibration $\mathrm{a}_{\mathrm{x} \_\mathrm{R} M S}, \mathrm{a}_{\mathrm{y}_{-} \mathrm{RMS}}, \mathrm{a}_{\mathrm{z}_{-} \mathrm{RMS}}$. The relationships between the data are presented in the function of technological parameters of milling.

\subsection{Neural networks specification}

The experimental data constituted the input data for the modelled prediction network of maximum and RMS values of vibration acceleration on axis $\mathrm{x}$. Similarly to the analysis of the cutting force components [23], it is on axis $\mathrm{x}$ that the analysed indicator of machinability reaches the highest magnitude, which is the reason for the selection of the particular component and axis. Vibration components in milling were modelled with the application of artificial neural networks [24] by means of Statistica Neural Networks software. Two network types were employed in the study: MLP (Multi-Layered Perceptron) and RBF (Radial Basis Function). In the former network model the following activation functions were implemented: linear, exponential, logistic, tanh and sinus, and its training involved the use of the following algorithms: BFGS gradient, conjugate gradient and the steepest descent. The activation functions used for the latter network, RBF, were: for hidden neurons Gaussian distribution, for the output neurons - linear function. This network was trained with RBFT algorithm. $80 \%$ of the results from milling test constituted the training data set, whereas the remaining $25 \%$ were used for the sake of validation. Owing to the small amount of experimental test results, we resigned from the test data set [25].
Each network was designed with one hidden layer. The input layer consisted of 3 neurons (cutting speed, feed per tooth and axial depth of cut), whereas the output layer - one neuron (vibration). The number of training epochs (200) was determined experimentally, as was the number of neurons in the hidden layer $(2 \div 9)$. The selection of the network was motivated by such factors as: quality of training and validation, training and validation errors determined by the least-squares algorithm.

\section{Test and simulation results}

\subsection{Analysis of results}

During the process of milling magnesium alloy AZ91D the values of vibration acceleration $a_{x}, a_{y}$ and $a_{z}$ were monitored. The results of observations are presented in Figs 1-3, according to cutting speed, feed per tooth and axial depth of cut. The obtained results subsequently allowed us to determine the maximum values of vibration acceleration components and their range, i.e. the difference between the highest and the lowest value. In several cases outliers and extremes were noted, which were connected with the increase in the value of vibration on the tool's entering into and exit from the machined component.

a)

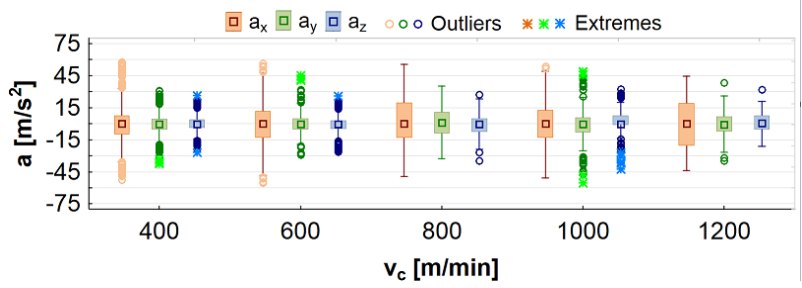

b)

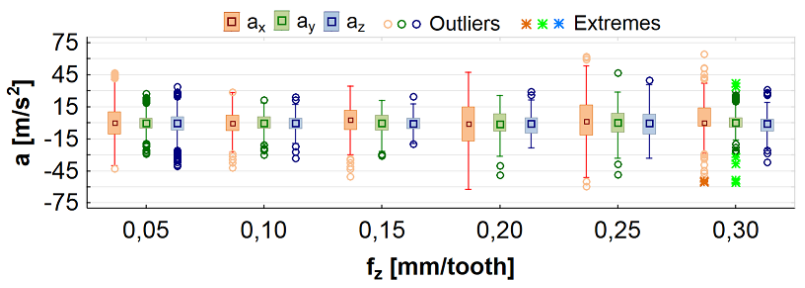

c)

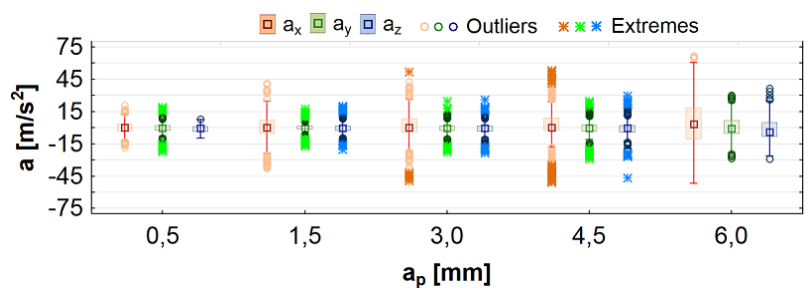

Fig. 1. Effect of technological parameters of milling on components of vibration acceleration $\mathrm{ax}_{\mathrm{x}}, \mathrm{a}_{\mathrm{y}}, \mathrm{a}_{\mathrm{z}}$ : a) $\mathrm{vc}_{\mathrm{c}}\left(f_{z}=0.15\right.$ $\mathrm{mm} /$ tooth, $\left.\left.\left.a_{p}=6 \mathrm{~mm}\right), \mathrm{b}\right) \mathrm{f}_{\mathrm{z}}\left(v_{c}=800 \mathrm{~m} / \mathrm{min}, a_{p}=6 \mathrm{~mm}\right), \mathrm{c}\right)$ ap $\left(v_{c}=800 \mathrm{~m} / \mathrm{min}, f_{z}=0.15 \mathrm{~mm} /\right.$ tooth $)$.

From Fig. 1a it becomes apparent that from the perspective of vibration the speeds of $800 \mathrm{~m} / \mathrm{min}$ and $1200 \mathrm{~m} / \mathrm{min}$ are the most advantageous, as cutting with these speeds was characterised by lowest ranges of outliers, while extremes were not recorded. Extreme vibration values were observed at $\mathrm{v}_{\mathrm{c}}: 400 \mathrm{~m} / \mathrm{min}$ and 
$1000 \mathrm{~m} / \mathrm{min}$. Fig. $1 \mathrm{~b}$ shows that altering the feed per tooth settings has little bearing on the increase of vibration range, given as outliers or extremes for particular components of vibration acceleration. The highest concentration of outliers/extremes emerged for $\mathrm{f}_{\mathrm{z}}=(0.05-0.1) \mathrm{mm} /$ tooth and $\mathrm{f}_{\mathrm{z}}=0.3 \mathrm{~mm} /$ tooth, whereas the lowest at $\mathrm{f}_{\mathrm{z}}=0.2 \mathrm{~mm} /$ tooth. The analysis of Fig. 1c clearly shows that for the PCD cutting tool the number of outliers and extremes is quite high, and that their concentrations occur at each axial depth of cut. The lowest value is observed for $a_{z}$ at $a_{p}=6 \mathrm{~mm}$, whereas the highest at $a_{p}=3$ and $a_{p}=4.5 \mathrm{~mm}$ (for all three components).

The obtained results (presented in the form of boxand-whisker plots) were employed to draw diagrams of relationships between maximum values of $a_{x}$ component of vibration acceleration, vibration amplitude $\mathrm{Aa}_{\mathrm{x}}$, and RMS vibration value $a_{x}$ RMS, in the function of technological parameters of milling (Figs 2a-2c). Furthermore, the figure shows standard deviation for particular components of vibration acceleration and vibration amplitude. Since the highest values of vibration acceleration are found on axis $\mathrm{x}$, and the lowest on axis $\mathrm{z}$, only the results of maximum values, amplitude and RMS vibration for the component on axis $\mathrm{x}$ will be reported.

a)

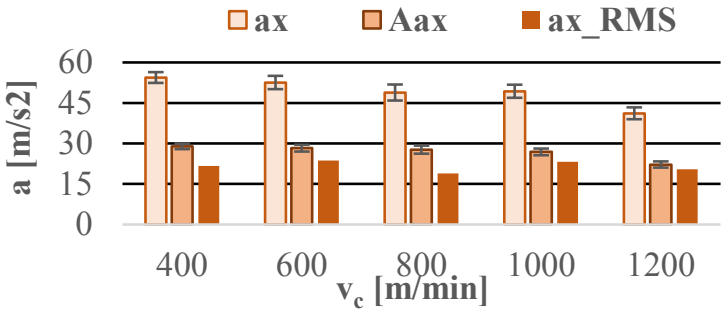

b)

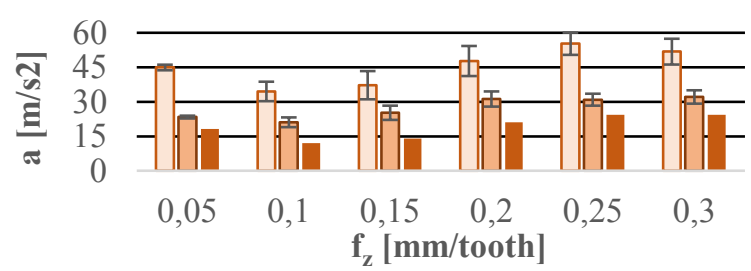

c)

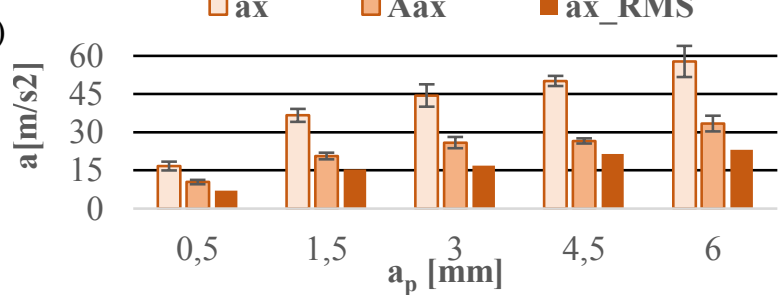

Fig. 2. Effect of $v_{c}, f_{z}, a_{p}$ on the $a_{x}$ component of vibration acceleration, vibration amplitude $\mathrm{Aa}_{\mathrm{x}}$ and $\mathrm{RMS}$ vibration $\mathrm{a}_{\mathrm{x} \_ \text {RMS }}$ for the change of: a) $\mathrm{v}_{\mathrm{c}}\left(f_{z}=0.15 \mathrm{~mm} /\right.$ tooth, $\left.a_{p}=6 \mathrm{~mm}\right)$, b) $\left.\mathrm{f}_{\mathrm{z}}\left(v_{c}=800 \mathrm{~m} / \mathrm{min}, a_{p}=6 \mathrm{~mm}\right), \mathrm{c}\right) \mathrm{a}_{\mathrm{p}}\left(v_{c}=800 \mathrm{~m} / \mathrm{min}, f_{z}=0.15\right.$ $\mathrm{mm} /$ tooth $)$.

As it may be seen in Fig. $2 \mathrm{a}$, the $\mathrm{a}_{\mathrm{x}}$ component and its amplitude $\mathrm{Aa}_{\mathrm{x}}$ tend to decrease in the entire range of cutting speeds. Maximum $a_{x}$ amounted to $a_{x}=54.41 \mathrm{~m} / \mathrm{s}^{2}$ at $\mathrm{v}_{\mathrm{c}}=400 \mathrm{~m} / \mathrm{min}$, while the lowest $\mathrm{a}_{\mathrm{x}}=41.17 \mathrm{~m} / \mathrm{s}^{2}$ at $\mathrm{v}_{\mathrm{c}}=1200 \mathrm{~m} / \mathrm{min}$. In the case of modifying $\mathrm{f}_{\mathrm{z}}$, for component $\mathrm{a}_{\mathrm{x}}$ and its amplitude $\mathrm{Aa}_{\mathrm{x}}$ the decrease in vibration is observed at $\mathrm{f}_{\mathrm{z}}=0.1 \mathrm{~mm}$, next the increase in the range of $f_{z}=(0.15 \div 0.25) \mathrm{mm}$, upon exceeding of which, the values decrease. The highest vibration for this component amounted to $\mathrm{a}_{\mathrm{x}}=55.25 \mathrm{~m} / \mathrm{s}^{2}$ at $\mathrm{f}_{\mathrm{z}}=0.25 \mathrm{~mm}$, while the lowest $a_{x}=34.49 \mathrm{~m} / \mathrm{s}^{2}$ at $\mathrm{f}_{\mathrm{z}}=0.1 \mathrm{~mm}$. From the analysis of Fig. 2c, showing the change in the value of $a_{p}$, it becomes evident that the increase in the axial depth of cut results in the increase in the value of component $a_{x}$. The highest value of vibration acceleration component at $a_{p}=6 \mathrm{~mm}$ is equal to: $a_{x}=57.80 \mathrm{~m} / \mathrm{s}^{2}$, and the lowest, at $a_{p}=0.5 \mathrm{~mm}, a_{x}=16.72 \mathrm{~m} / \mathrm{s}^{2}$.

Figs 2a-2c show that the RMS vibration shows considerable dependence on the amplitude of vibration, which in the majority of cases amounts to $60 \%$ of the value. As the analysis of experimental data shows, the highest risk of the spindle and the cutting tool damage occurs when cutting at (Fig.2a) $v_{c}=1000 \mathrm{~m} / \mathrm{min}$, and the lowest at $\mathrm{v}_{\mathrm{c}}=400 \mathrm{~m} / \mathrm{min}\left(\mathrm{f}_{\mathrm{z}}=0.15 \mathrm{~mm} /\right.$ tooth, $\left.\mathrm{a}_{\mathrm{p}}=6 \mathrm{~mm}\right)$. With regard to feed per tooth (Fig. $2 b$ ) the range $f_{z}=$ $0.05-0.15 \mathrm{~mm} /$ tooth seems the most adequate (for $\mathrm{v}_{\mathrm{c}}=800 \mathrm{~m} / \mathrm{min}, \mathrm{ap}=6 \mathrm{~mm}$ ). Comparing values of RMS for modifying axial depth of cut (Fig. 2c) we may see that the highest values are recorded for $a_{p}=4.5-6 \mathrm{~mm}$.

\subsection{Simulation results}

The experimental part of the study has provided data for the prediction of maximum vibration acceleration and RMS vibration on axis $\mathrm{x}$.

Table 1. Network parameters for the simulation of RMS vibration $a_{x_{-} R M S}$ and maximum vibration $a_{x}$ on axis $\mathrm{x}$.

\begin{tabular}{|c|c|c|c|}
\hline \multicolumn{4}{|c|}{ RMS vibration value on axis $\mathrm{x} a_{x_{-} R M S}$} \\
\hline Network No. & 1 & 2 & 3 \\
\hline Network name & MLP 3-4-1 & MLP 3-2-1 & MLP 3-4-1 \\
\hline $\begin{array}{l}\text { Quality of training/ } \\
\text { validation [\%] }\end{array}$ & $\begin{array}{c}96.27 / \\
98.14\end{array}$ & $\begin{array}{c}95.04 / \\
99.96\end{array}$ & $\begin{array}{c}96.55 / \\
94.91\end{array}$ \\
\hline $\begin{array}{l}\text { Error of training/ } \\
\text { validation }\end{array}$ & $\begin{array}{c}0.828 / \\
1.265 \\
\end{array}$ & $\begin{array}{l}1.097 / \\
1.649 \\
\end{array}$ & $\begin{array}{l}0.767 / \\
1.337 \\
\end{array}$ \\
\hline Training algorithm & $\begin{array}{c}\text { Conjugate } \\
\text { gradient } \\
199\end{array}$ & $\begin{array}{l}\text { BFGS } \\
1155\end{array}$ & BFGS 176 \\
\hline $\begin{array}{l}\text { Activation (hidden } \\
\text { / output) }\end{array}$ & $\begin{array}{l}\text { Logistic } \\
\text { /Linear }\end{array}$ & $\begin{array}{c}\text { Tanh/ } \\
\text { Linear }\end{array}$ & $\begin{array}{l}\text { Logistic } \\
\text { /Linear }\end{array}$ \\
\hline \multicolumn{4}{|c|}{ Maximum vibration on axis $\mathrm{x} a_{x}$} \\
\hline Network No. & 4 & 5 & 6 \\
\hline Network name & RBF 3-6-1 & MLP 3-9-1 & MLP 3-2-1 \\
\hline $\begin{array}{l}\text { Quality of training/ } \\
\text { validation }[\%]\end{array}$ & $\begin{array}{c}98.04 / \\
90.29\end{array}$ & $\begin{array}{l}96.35 / \\
95.71\end{array}$ & $\begin{array}{c}98.83 / \\
81.47\end{array}$ \\
\hline $\begin{array}{l}\text { Error of training/ } \\
\text { validation }\end{array}$ & $\begin{array}{l}0.902 / \\
2.089 \\
\end{array}$ & $\begin{array}{l}4.066 / \\
4.426 \\
\end{array}$ & $\begin{array}{l}1.254 / \\
5.191 \\
\end{array}$ \\
\hline Training algorithm & RBFT & BFGS 170 & $\begin{array}{l}\text { Conjugate } \\
\text { gradient } \\
299\end{array}$ \\
\hline $\begin{array}{l}\text { Activation (hidden } \\
\text { / output) }\end{array}$ & $\begin{array}{l}\text { Gaussian/ } \\
\text { Linear }\end{array}$ & $\begin{array}{l}\text { Sinus/ } \\
\text { Sinus }\end{array}$ & $\begin{array}{l}\text { Tanh/ } \\
\text { Linear }\end{array}$ \\
\hline
\end{tabular}

In the simulation of each scenario we considered 100 networks that were subsequently limited to 3 best-fitting models, according to the indicators detailed in Test and simulation methodology section. Network characteristics are presented in Table 1. 
The analysis of data from Table 1 indicates that the values of RMS vibration on axis $\mathrm{x}, \mathrm{a}_{\mathrm{x}}$ RMS, are the most favourable for network 3, MLP 3-4-1, while for the maximum value of vibration acceleration on axis $\mathrm{x}$, ax for network 4, RBF 3-6-1.

The graphical representation of results was limited so as to maintain the maximum $3 \mathrm{D}$ arrangement of axes in the presented results one of the inputs is always constant. Fig. 3 shows exemplary simulation results for network MLP 3-4-1, and in Fig. 4 - for RBF 3-6-1.

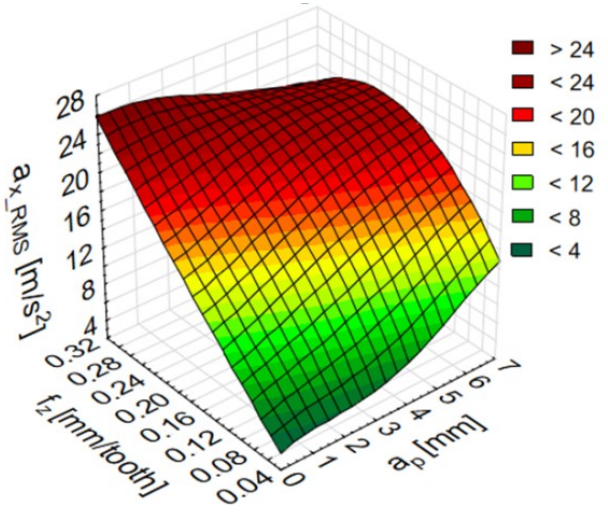

Fig. 3. Results from the simulation of RMS vibration on axis $x$ $a_{x \_R M S}$, depending on feed per tooth $f_{z}$, axial depth of cut $a_{p}$ and cutting speed $v_{c}=800 \mathrm{~m} / \mathrm{min}$ for network MLP 3-4-1.

a)

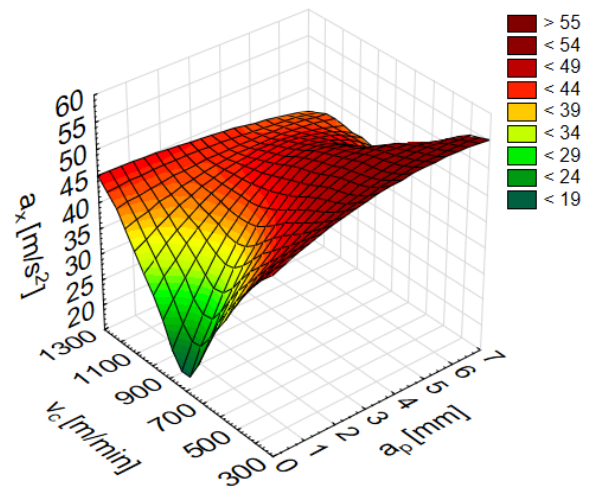

b)

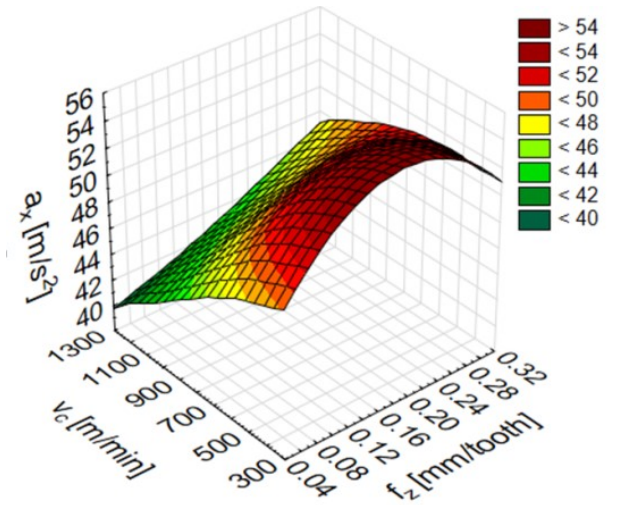

Fig. 4. Results from the simulation of maximum vibration on axis $\mathrm{x} a_{x}$ for network RBF 3-6-1, depending on cutting speed $v_{c}$ and: a) axial depth of cut $a_{p}$ and feed per tooth $f_{z}=0.15$ $\mathrm{mm} /$ tooth, b) feed per tooth $f_{z}$ and axial depth of cut $a_{p}=6 \mathrm{~mm}$.

The networks developed in the simulation works represent the behaviour of vibration acceleration maximum and RMS vibration on axis $\mathrm{x}$, which are obtained for particular modifiable parameters considered in the study: cutting speed, feed per tooth and axial depth of cut. As a result, by entering in Statistica certain input parameters we obtain the value of vibration $a_{x}$ or $a_{x} R M S$, depending on which network was launched.

The verification of simulations and the accuracy of the model were carried out by comparing the real vibration acceleration values obtained from experimental tests with predictions. The simulated maximum vibration $\left(a_{x}\right)$ and RMS vibration $\left(a_{x_{-} R M S}\right)$ values on axis $\mathrm{x}$ are shown in Fig. 5.

a)

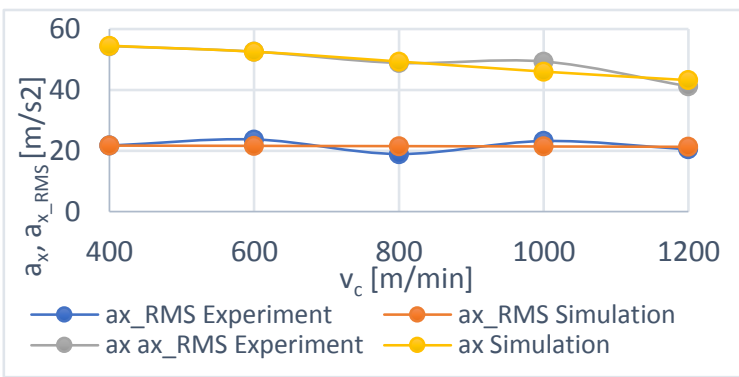

b)

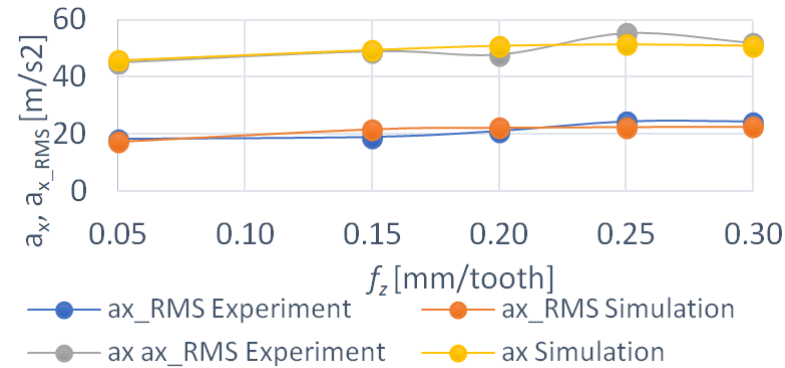

c)

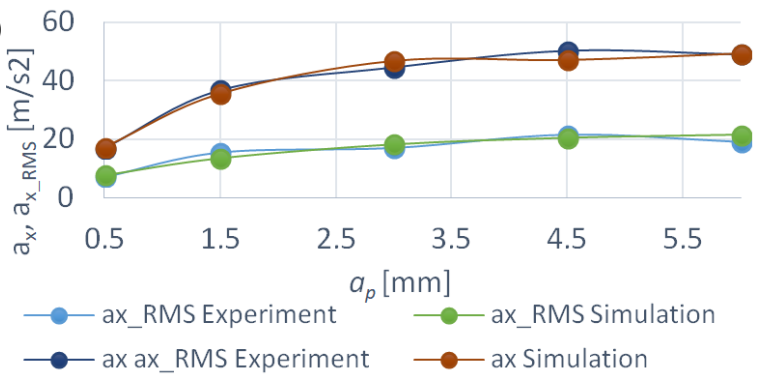

Fig. 5. Comparison of maximum vibration $\left(a_{x}\right)$ and RMS vibration $\left(a_{x_{-} R M S}\right)$ on axis $\mathrm{x}$ with experimental data: a) $f_{z}=0.15$ $\mathrm{mm} / \mathrm{rev}$.] $a_{p}=6 \mathrm{~mm}$ and modifiable parameter $\left.v_{c}, \mathrm{~b}\right) v_{c}=800$ $\mathrm{m} / \mathrm{mm}, a_{p}=6 \mathrm{~mm}$ and modifiable parameter $f_{z}$. c) $f_{z}=0.15$ $\mathrm{mm} / \mathrm{rev} ., v_{c}=800 \mathrm{~m} / \mathrm{mm}$ and modifiable parameter $a_{p}$.

The predictive error in both cases did not exceed $10 \%$. It may be therefore concluded that the networks offer satisfactory accuracy level and therefore may be applied as decision-making aid tool.

\section{Summary and conclusions}

Analysis of milling parameters impact highlights the strong correlation between the selection of suitable technological parameters and vibration acceleration. The measurements and analysis of their results lead to the following general conclusions:

- the character of vibrations responds to technological parameters, as well as to the type and geometry of the cutter tool, 
- $\quad$ stability lobes are obtained by modifying machining parameters: reducing axial depth of cut and feed per tooth, or increasing cutting speed,

- regarding $\mathrm{v}_{\mathrm{c}}$, the lowest vibrations occur at cutting speed of $1200 \mathrm{~m} / \mathrm{min}$,

- increase in feed results in increase in vibration acceleration, vibration amplitude, standard deviation and RMS vibration,

- regarding $\mathrm{f}_{\mathrm{z}}$, the lowest vibrations occur in the range of $\mathrm{f}_{\mathrm{z}}=(0.1-0.15) \mathrm{mm}$, which denotes the most appropriate range for $\mathrm{f}_{\mathrm{z}}$, - whereas the highest vibrations at $\mathrm{f}_{\mathrm{z}}=(0.25-0.3) \mathrm{mm}$,

- increase in $a_{p}$ results in increase in vibration of particular components, amplitudes, standard deviation and RMS vibration (the lowest values were obtained at $a_{p}=0.5 \mathrm{~mm}$, and the highest at $a_{p}=6$ $\mathrm{mm}$ ),

- artificial neuron network models developed by means of Statistica enable determination of maximum and root-mean-square values of vibration acceleration on axis $\mathrm{x}$,

- results of simulation provide technologists with aid in the area of specification of machining parameters in milling of AZ91D magnesium alloys with PCD cutter tools,

- the presented vibration simulation could provide contribution to a computer decision-making aid system,

- the presented vibration simulation proves that artificial neuron networks offer sufficient quality and accuracy to be applied in prediction of nonlinear machining processes, such as milling.

\section{References}

1. P. Zgórniak, W. Stachurski, D. Ostrowski, Stroj. Vestnik-J Mech. E. 62, 657-664 (2016)

2. A.Weremczuk, R. Rusinek, J. Warmiński, Procedia CIRP, 31, 82 - 87 (2015)

3. W. Adamski, Adv. Manuf. Sci. Technol. 34, 73-84 (2010)

4. I. Zagórski, M. Kulisz, A. Semeniuk, A. Malec, Adv. Sci. Technol. Res. J. 11, 261-269 (2017) https://doi.org/10.12913/22998624/76546

5. Ł. Żyłka, M. Płodzień, Mechanik, 2, 1-12 (2013)
6. S. Seguy, T. Insperger, L. Arnaud, G. Desseiu, G. Peigne, Int. J Adv. Manuf. Tech. 48, 883-895 (2010)

7. R. Rusinek, K. Zaleski, Meccanica, 51, 1275-1286 (2016)

8. Y. Yang, W-H. Zhang, Y-Ch. Ma, Wan M., Int. J Mach. Tools Manuf. 109, 36-48 (2016)

9. S. Wu, R. Li, X. Liu, L. Yang, M. Zhu, Procedia CIRP, 56, 422 - 427 (2016)

10. A. Comak, E. Budak, Precis. Eng. 47, 459-468 (2017)

11. M. Eynian, Int. J Mach. Tools Manuf. 90, 44-49 (2015)

12. G. Quintana, J. Ciurana, Int. J Mach. Tools Manuf. 51, 363-376 (2011)

13. J. Munoa, X. Beudaert, Z. Dombovari, Y. Altintas, E. Budak, C. Brecher, G. Stepan, CIRP J. Manuf. Sci. Technol. 65, 785-808 (2016)

14. T.Ch. Hsiao, S.Ch. Huang, Adv. Mater. Res. 887888, 1200-1204 (2014)

15. J.V. Le Lan, A. Marty, J.F. Debongnie, Int. J Mach. Tool and Manuf., 47, 1493-1496 (2007)

16. M. Pajor, B. Powałka, M. Hoffmann, Inżynieria Maszyn, 16, 95-112 (2011)

17. R. Madoliat, S. Hayati, A.G. Ghalebahman, J Adv. Mech. Des. Sys. Manuf. 5, 115-128 (2011)

18. P.A. Bąk, K. Jemielniak, Mechanik, 10, 1418-1419 (2016)

19. P. Szulewski, D. Śniegulska-Grądzka, Mechanik, 3, 170-175 (2017)

20. J. Burek, R. Babiarz, P. Słutkowicz M. Sałata, Mechanik, 11,1652-1653 (2016)

21. J. Friedrich, Ch. Hinze, A. Renner, A. Verl, A. Lechler, Robot. Comput.-Integr. Manuf. 43, 124134 (2017)

22. J. Lipski, K. Zaleski, ITM Web Conf. 15, 01005 (2017) https://doi.org/10.1051/itmconf/20171501005

23. I. Zagórski, M. Kulisz, A. Semeniuk, ITM Web Conf. 15, 02001 (2017) https://doi.org/10.1051/itmconf/ 20171502001

24. G. Kłosowski, T. Rymarczyk, A. Gola., Appl. Sci. 8(9), 1457 (2018) https://doi.org/10.3390/app8091457

25. http://www.statsoft.pl/Portals/0/Downloads/Sieci\%2 Oneuronowe .pdf 